\title{
Screening for Lignin-degrading Actinomycetes and Characterization of their Activity against $\left.\right|^{14} \mathrm{C} \mid$ Lignin-labelled Wheat Lignocellulose
}

\author{
By ALAN J. MCCARTHY* AND PAUL BRODA \\ Department of Biochemistry and Applied Molecular Biology. University of Manchester Institute \\ of Science and Technology, PO Box 88. Manchester M60 IQD. UK
}

(Receired 5 April 1984; revised 4 June 1984)

\begin{abstract}
A sedimentation chamber and Andersen sampler were used to isolate a range of actinomycetes on selective and non-selective media. The occurrence of different actinomycete groups in natural substrates was compared and strains were screened for the ability to degrade ball-milled straw or to grow on lignin-related phenolic compounds. Evidence for ligninolytic activity in representatives of several genera was obtained by assaying ${ }^{1+} \mathrm{CO}_{2}$ evolution from $\left[{ }^{1+} \mathrm{C}\right]$ ligninlabelled wheat lignocellulose. Most of the straw-degrading isolates were assigned to the genera Thermomonospora and Micromonospora, but only representatives of the latter were found to be active against $\left[{ }^{1+} \mathrm{C}\right]$ lignin. Of the non-straw-degrading strains also examined, some which could utilize phenolic substrates produced ${ }^{14} \mathrm{CO}_{2}$ from the [lignin-14 $\mathrm{C}$ lignocellulose, and two of these were selected for further study. These strains, Thermomonospora mesophila and a Streptomyces sp., attacked $\left[{ }^{14} \mathrm{C}\right]$ lignin yielding ${ }^{14} \mathrm{CO}_{2}$ and water-soluble ${ }^{14} \mathrm{C}$-labelled compounds during primary growth. This activity was not accounted for by the utilization of phenolic acids linked to the carbohydrate fraction of wheat lignocellulose and was unaffected by cultural parameters known to influence lignin degradation by white-rot fungi.
\end{abstract}

\section{INTRODUCTION}

Actinomycetes are widely distributed in natural substrates such as soils and compost, where they have an important role in the recycling of organic material (Lacey, 1973). They are prokaryotes which usually exhibit a hyphal growth form and thus are well-equipped to penetrate and degrade the lignocellulose of plant cell walls. However, lignocellulose degradation in natural substrates is largely attributed to fungi and, in this respect, the importance of actinomycetes may have been underestimated. Cellulolytic activity has been described in a range of actinomycete genera (Stutzenberger, 1972; Sandrak, 1977; Crawford, 1978), Thermomonospora, which can degrade cellulose, hemicellulose and pectin (McCarthy \& Cross, 1984), being particularly noteworthy. Claims that actinomycetes are also involved in the degradation of lignin (Waksman \& Cordon, 1939) have only recently been confirmed (Crawford, 1978; Haider et al., 1978).

The complex structure of lignin has necessitated the application of assays in which the substrate is lignocellulose specifically ${ }^{14} \mathrm{C}$-labelled in the lignin component. This approach has been used by Crawford and co-workers to demonstrate ligninolytic activity in Streptomyces strains (Crawford, 1978; Phelan et al., 1979) and similarly by Trojanowski and co-workers working with strains of Nocardia (Haider et al., 1978) and Rhodococcus (Trojanowski et al., 1977). Since there have been no reports of lignin degradation by other actinomycetes, one objective of the investigation reported here was to extend the range of taxa studied. Isolation methods which give the best recovery of actinomycetes are often biased towards streptomycetes, whose rapid proliferation together with bacterial growth can preclude the isolation of strains belonging to other actinomycete groups. In the work described in this paper, an alternative strategy, in which propagules were suspended in air prior to colony formation on various selective media, was used to obtain a range of actinomycete isolates and provide some information on their occurrence and distribution. 
The physiology of lignin biodegradation has been extensively studied in relation to the attack of wood and synthetic lignins by the white-rot fungus Phanerochaete chrysosporium. This is now a relatively well-defined system in which lignin degradation to $\mathrm{CO}_{2}$ is a secondary metabolic activity requiring high $\mathrm{O}_{2}$ tension (Kirk \& Fenn, 1982) and involving production of hydroxyl radical (Forney et al., 1982) and an $\mathrm{H}_{2} \mathrm{O}_{2}$-dependent extracellular enzyme (Tien \& Kirk, 1983). Actinomycete lignin degradation is, by comparison, poorly understood, although Crawford and co-workers have made some important observations with Streptomyces viridosporus. The lignin substrate is primarily solubilized in the growth medium, in the form of lignin-derived monomers (Crawford, 1981) and a substantially degraded polyphenolic polymeric lignin (APPL) (Crawford et al., 1983). Grass lignins are more susceptible to this form of attack than softwood and hardwood lignins (Antai \& Crawford, 1981).

We have determined the ligninolytic potential of a range of actinomycete strains, selected for their ability to degrade grass lignocellulose or utilise lignin-derived compounds, by measuring ${ }^{14} \mathrm{CO}_{2}$ evolution from [ ${ }^{14} \mathrm{C}$-lignin-labelled wheat lignocellulose. The radiolabelled substrate was also used to characterize grass lignin degradation by two actinomycetes.

\section{METHODS}

Isolation of mesophilic and thermophilic actinomycetes. Samples of soil, leaf litter, mushroom compost, garden compost and rotted wood were dried at $37^{\circ} \mathrm{C}$ and used as sources of actinomycete isolates. A sedimentation chamber/Andersen sampler method (McCarthy \& Cross, 1981) was used routinely. A dilution plating method incorporating mild heat treatment (Rowbotham \& Cross, 1977) was also used to isolate mesophiles from mushroom compost. The following isolation media were used. (i) Half-strength Tryptone soy agar ( $\left.\frac{1}{\mathrm{t}} \mathrm{TSA}\right)$ which con-

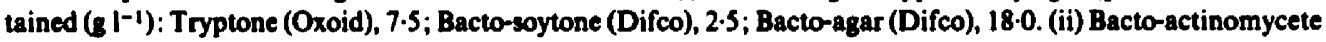
isolation agar (Difco). (iii) M3 agar (Rowbotham \& Cross, 1977). (iv) Half-strength Nutrient agar (Oxoid CM3) ( NA) with and without rifampicin ( $5 \mu \mathrm{g} \mathrm{ml} \mathrm{l}^{-1}$, Sigma) or novobiocin $\left(25 \mu \mathrm{g} \mathrm{ml} \mathrm{m}^{-1}, \mathrm{BDH}\right)$ filter-sterilized and added to the medium after autoclaving. (v) Minimal medium (Stutzenberger, 1972) plus Bacto-agar (18.0 $\mathrm{g} \mathrm{l}^{-1}$ ) and vitamin-free Casamino acids (0.25 g 1-1, Difco). All of the above media were adjusted to $\mathrm{pH} \mathrm{8.0-8.5}$ and, after autoclaving, a filter-sterilized solution of the antifungal antibiotic cycloheximide (Bochringer) was added to a final concentration of $50 \mu \mathrm{gl}^{-1}$. For direct isolation of lignocellulose-degrading actinomycetes, a separately autoclaved suspension of vibratory ball-milled straw (mean particle size $5 \mu \mathrm{m}$ diameter) was added to media (iii), (iv) and (v). Potential Kraft-lignin degraders were isolated on medium (iii) to which Indulin AT (Westvaco, North Charleston, S. Carolina, USA), dissolved in $0.1 \mathrm{~m}-\mathrm{NaOH}$ and filter-sterilized, had been added to a final concentration of $0.1 \%(w / v)$. Isolation plates were incubated at $50^{\circ} \mathrm{C}$ for $5 \mathrm{~d}$ or $30^{\circ} \mathrm{C}$ for up to $21 \mathrm{~d}$. Actinomycete colonies were identified by direct microscopic examination of isolation plates using a $\times 32$ long-working-distance objective lens (Leitz Wetzlar, FRG).

Primary screen for degradation of ligmocellulose and related substrates. Strains were point-inoculated onto the surface of Petri dishes containing medium (v) plus $0.3 \%$ (w/v) ball-milled straw. Cultures incubated at 30,37 or $50^{\circ} \mathrm{C}$ were examined at intervals up to 28,14 and $7 \mathrm{~d}$, respectively, and scored for clearing of the insoluble substrate beneath and around the area of growth.

Sodium propionate was omitted from medium (iii) to provide a test medium for the utilization of aromatic compounds. Where necessary, the medium was supplemented with $0.01 \%$ (w/v) yeast extract to ensure that growth was limited by the absence of carbon source only. Growth enhancement in the presence of the test substrate indicated utilization, with D-glucose $(0.05 \%$ or $0.1 \%, w / v)$ as the positive control. The following compounds were tested at $0.05 \%(w / v)$ : ferulic acid; syringic acid; Indulin AT $(0.1 \%, w / v$, also). Indulin AT was added as described for the isolation medium and the remainder were prepared as filter-sterilized stock solutions in $0.5 \mathrm{M}-\mathrm{NaOH}$, adjusted to pH 8.0-9.0 with $1 \mathrm{M}-\mathrm{HCl}$. Agar media were dispensed in $2.5 \mathrm{ml}$ amounts in Replidishes (Sterilin) and inoculated with single-drop samples of spores and hyphae suspended in distilled water. Cultures were incubated at 30,37 or $50^{\circ} \mathrm{C}$ and growth scored at intervals up to 21,14 and $7 \mathrm{~d}$, respectively. Two strains which gave positive responses with aromatic substrates were further tested for the ability to utilize indulin $\mathrm{AT}$ and ferulic acid in liquid culture. The test substrates were added to a final concentration of 0.1 and $0.05 \%(w / v)$ of a medium that contained $\left(1^{-1}\right)$ : $\left(\mathrm{NH}_{4}\right)_{2} \mathrm{SO}_{4}, 0.1 \mathrm{~g} ; \mathrm{NaCl}, 0.3 \mathrm{~g} ; \mathrm{MgSO}_{4} .7 \mathrm{H}_{2} \mathrm{O}, 0.1 \mathrm{~g} ; \mathrm{CaCO}_{3} 0.02 \mathrm{~g} ; \mathrm{FeSO}_{4} .7 \mathrm{H}_{2} \mathrm{O}, 200 \mu \mathrm{g} ; \mathrm{ZnSO}_{4} .7 \mathrm{H}_{2} \mathrm{O}$, $180 \mu \mathrm{g} ; \mathrm{MnSO}_{4} .7 \mathrm{H}_{2} \mathrm{O}, 20 \mu \mathrm{g}$; yeast extract (Oxoid), $0.1 \mathrm{~g}$. After autoclaving, medium was buffered with sterile 1 M-potassium phosphate buffer, $\mathrm{pH} 8.0\left(50 \mathrm{ml} \mathrm{l}^{-1}\right)$. Cultures $(20 \mathrm{ml})$ were incubated with shaking at $37^{\circ} \mathrm{C}$ and growth scored at intervals up to $10 \mathrm{~d}$. Three strains were also tested for utilization of aromatic compounds in the presence and absence of glucose (Sundman \& Nase, 1971). Ferulic acid, syringic acid or Indulin AT were added at $0.05 \%(w / v)$ to a basal medium which contained : $0.2 \mathrm{M}$-Tris buffer ( $\mathrm{pH} 7.6), 100 \mathrm{ml}$; vitamin-free Casamino acids (Difco), $1.0 \mathrm{~g}$; thiamin, $100 \mu \mathrm{g}$; biotin, $100 \mu \mathrm{g}$; D-glucose, $2.0 \mathrm{~g}$; Bacto-agar (Difco), 18.0 g; distilled water, $900 \mathrm{ml}$. Thiamin, biotin and D-glucose were prepared as filter-sterilized solutions and added to the autoclaved medium. 
Media were dispensed into Petri dishes, point-inoculated and incubated as described above. After $14 \mathrm{~d}$, growth was removed and the plates flooded with $10 \mathrm{ml}$ of a $1.0 \%(w / v)$ solution of ferric chloride/potassium ferricyanide. The reagent was poured of after $10 \mathrm{~min}$, leaving the agar stained blue or green where the aromatic compounds were present. A yellowish zone where growth had been removed was interpreted as evidence for degradation of these compounds.

Assay for (lignin-14C ${ }^{1}$ ignocellulose degradation $10{ }^{14} \mathrm{CO}_{2}$. Radiolabelled wheat lignocellulose was prepared and analysed as described previously (McCarthy $e t$ al., 1984) and had a specific activity of $3.04 \times 10^{4}$ d.p.m. $\mathrm{mg}^{-1}$. Approximately $2 \mathrm{mg}$ [/ignin-14 C]ignocellulose and $30 \mathrm{mg}$ ball-milled straw were added to $250 \mathrm{ml}$ conical flasks each containing $15 \mathrm{ml}$ of medium. The medium had the same composition as that used to teat aromatic substrate utilization in liquid culture except that the yeast extract concentration was increased to $1.0 \mathrm{~g}^{-1}$. After autoclaving, $0.75 \mathrm{ml}$ I M-potassium phosphate buffer, pH 8.0, was added to each flask. Suspensions of actinomycete hyphac and spores in sterile distilled water were used as inocula. The flasks were sealed, incubated at 30,37 or $50{ }^{\circ} \mathrm{C}$ and flushed with $100 \% \mathrm{O}_{2}$ at $3 \mathrm{~d}$ intervals. The ${ }^{1+} \mathrm{CO}_{2}$ was trapped and radioactivity counted as described previously (McCarthy et al., 1984). At the end of the experiments, portions of culture medium were examined microscopically and by subculturing on nutrient media to confirm that the cultures were axenic.

Characterization of [14 Clignin degradation. Thermomonospora mesophila DSM 43048 and Streptomyces sp. MT813 were identified as active lignin degraders and selected for further study. The efiect of a number of parameters on ${ }^{14} \mathrm{CO}_{2}$ evolution by these strains at $37^{\circ} \mathrm{C}$ was investigated using the assay method described above, except that cultures were flushed at varying time intervals. Evolution of ${ }^{14} \mathrm{CO}_{2}$ was compared in cultures containing a range of yeast extract concentrations $\left(0,0.5,1.0\right.$ and $\left.2.0 \mathrm{~g}^{-1}\right)$, cultures grown in air rather than $100 \% \mathrm{O}_{2}$ and in cultures incubated with shaking. Degradation of [lignin- ${ }^{14} \mathrm{C}$ llignocellulose autoclaved dry at $121^{\circ} \mathrm{C}$ for $3 \mathrm{~h}$ or treated twice with cellulase to remove carbohydrate esters of phenolic acids (McCarthy et al., 1984) was also examined. Finally, solubilization of $\left[{ }^{14} \mathrm{C}\right]$ lignin was monitored in parallel with ${ }^{14} \mathrm{CO}_{2}$ evolution by aseptically removing $700 \mu \mathrm{l}$ samples of the culture medium at time intervals and counting radioactivity in membrane-filtered (Millipore; $0.22 \mu \mathrm{m}$ pore size) portions. Evolution of ${ }^{14} \mathrm{CO}_{2}$ from spent culture filtrates was also assayed by adding known amounts of solubilized ${ }^{14} \mathrm{C}$ to fresh actinomycete cultures.

\section{RESULTS}

\section{Occurrence and distribution of actinomycetes}

Thermophilic actinomycetes were present in very high numbers in the samples of compost and were isolated together with many Bacillus colonies. In mushroom compost, 'Thermomonospora fusca' and Thm. curvata (white thermomonosporas) predominated (>500 colonies per stack of Andersen sampler plates) with 'Thm. chromogena', Streptomyces spp. and Thermoactinomyces spp. present in much lower numbers ( $<50$ colonies). The thermophilic actinomycete population of garden compost was comparable in size but streptomycetes and thermoactinomycetes were more numerous, although no single actinomycete group was clearly predominant. Few thermophilic actinomycetes were isolated from samples of soil, leaf litter and rotted wood where they were probably present as dormant spores.

Mushroom compost proved to be an excellent source of mesophilic actinomycetes as well as thermophiles. A large number of unidentified actinomycetes, mostly nocardioform in appearance, were observed on isolation plates in addition to micromonosporas [ $\left.10^{7}(\mathrm{~g} d r y \mathrm{wt})^{-1}\right]$ and a range of streptomycetes $\left[10^{8}(\mathrm{~g} \mathrm{dry} \mathrm{wt})^{-1}\right]$. These mesophilic actinomycete groups were recovered from all of the substrates using the sedimentation chamber and Andersen sampler, although numbers were particularly low in the samples of soil and rotted wood. Incorporation of novobiocin $\left(25 \mu \mathrm{g} \mathrm{ml}^{-1}\right)$ in $\frac{1}{2} \mathrm{NA}$ produced an isolation medium which was selective for thermoactinomycetes when used at $50^{\circ} \mathrm{C}$ (Cross, 1968), and for micromonosporas at $30^{\circ} \mathrm{C}$ (Orchard. 1980). Similarly, addition of rifampicin $\left(5 \mu \mathrm{g} \mathrm{ml}^{-1}\right)$ rendered the medium selective for 'Thm. chromogena' at $50^{\circ} \mathrm{C}$. Rifampicin also caused a drastic reduction in the numbers of bacteria isolated from mushroom compost at $30^{\circ} \mathrm{C}$, while permitting the growth of certain streptomycetes and unidentified actinomycetes. A number of these unidentified mesophiles were presumptively identified as actinomadurae, which are known to be efficiently isolated on rifampicin-containing media (Athalye et al., 1980).

No thermophilic actinomycetes were isolated on Bacto-actinomycete isolation agar (Difco) and the recovery of mesophiles other than streptomycetes on this medium was poor. The remaining non-selective isolation media generally yielded a comparable range and number of actinomycetes, although thermophiles grew poorly on M3 agar and were therefore difficult to 
identify. The reduced bacterial growth on isolation plates from the Andersen sampler permitted observation of clear zones around actinomycete colonies on agar media containing ball-milled straw. On plates incubated at $50^{\circ} \mathrm{C}$, all white thermomonospora colonies and a few of the ${ }^{\circ} \mathrm{Thm}$. chromogena' colonies were surrounded by well-defined areas of clearing. Straw-degrading white thermomonosporas were also isolated at $30^{\circ} \mathrm{C}$ and these strains were invariably capable of growth at $50^{\circ} \mathrm{C}$. The only other major actinomycete group found to contain a high proportion of straw-degrading strains was the genus Micromonospora. These organisms grew slowly at $30^{\circ} \mathrm{C}$ and produced indefinite zones of clearing after 10-21 d incubation. Straw degradation by other actinomycete isolates was only occasionally recorded. Addition of Kraft lignin (Indulin AT) to M3 agar had no apparent effect on the numbers and types of actinomycetes isolated on this medium.

\section{Degradation of lignin and related substrates}

The total culture collection (400 strains approx.) was tested for straw degradation but definite evidence of activity was found in only 77 strains. Of these, 44 were thermomonosporas, 21 micromonosporas, 7 streptomycetes and 5 unidentified actinomycetes. Clear zones around colonies on agar plates containing ball-milled straw were found to be the result of cellulolytic activity, and did not correlate with the degradation of other related substrates e.g. xylan or carboxymethylcellulose. A proportion of the culture collection ( 50 strains) chosen to represent taxonomic groupings was also tested for the ability to utilize aromatic compounds as carbon sources. Seven ferulic acid-utilizing strains were identified in this way, only two of which could also utilize Kraft lignin. One straw-degrading actinomycete, Micromonospora sp. MT807, exhibited a weak growth response when ferulic acid or $K$ raft lignin were added to the carbon utilization test medium.

A total of $\mathbf{4 6}$ strains were tested for grass lignin degradation by the radiometric assay and some of the results are presented in Table 1 . Thermophilic thermomonosporas were the most active straw-degraders examined but none of the strains tested showed significant activity against radiolabelled lignin. However, limited ${ }^{4}{ }^{4} \mathrm{CO}_{2}$ evolution was detected in other straw-degrading actinomycetes, notably strains of Micromonospora. The results presented in Table 1 also show that utilization of ferulic acid or Kraft lignin does not necessarily imply the ability to attack native lignin. Nevertheless, the best lignin degraders, Actinomadura sp. MT809, Streptomyces sp. MT81 3 and Thm. mesophila, were found amongst this group of strains which could utilize aromatic compounds. All three strains grew well on ferulic acid but none could utilize the dimethoxylated compound, syringic acid. Only Thm. mesophila showed a significant growth response when Kraft lignin was added to carbon-deficient basal medium. The nocardioform isolate MT803 grew well on ferulic acid, Kraft lignin and syringic acid but could not degrade $\left[{ }^{14} \mathrm{C}\right]$ lignin-labelled wheat lignocellulose to ${ }^{14} \mathrm{CO}_{2}$.

The ferulic acid and Kraft-lignin utilization patterns of Thm. mesophila and Streptomyces sp. MT813 (Table 1) were found to be reproducible in the basal liquid medium used for the $\left[{ }^{14} \mathrm{C}\right]$ lignin degradation assay. However, there was a poor correlation between the observation of growth responses in the presence of aromatic substrates and the colour test devised by Sundman \& Näse (1971). In both the absence and presence of glucose, the Nocardia autotrophica strains gave positive reactions when ferulic acid plates were flooded with the test reagent. These strains also exhibited a growth response in basal medium supplemented with ferulic acid. Thm. mesophila, which grew on ferulic acid and Kraft lignin in both agar and broth cultures, was, however, scored negative for aromatic compound utilization by the Sundman \& Näse test. A possible explanation is that utilization of propane side chains and methoxyl groups without aromatic ring cleavage would not be detected by this test but could nevertheless result in growth on ferulic acid and Kraft lignin.

\section{Characteristics of lignin degradation by actinomycetes}

Thm. mesophila and Streptomyces sp. MT813, two unrelated actinomycetes which appeared to be the best lignin degraders, were used to investigate the effects of several parameters on ${ }^{14} \mathrm{CO}_{2}$ evolution from [ lignin- $^{-14}$ C]lignocellulose. Yeast extract concentration is an important cultural 
Table 1. Activity of actinomycetes against stran; lignin-related compounds and

['C Clignin-labelled wheat lignocellulose

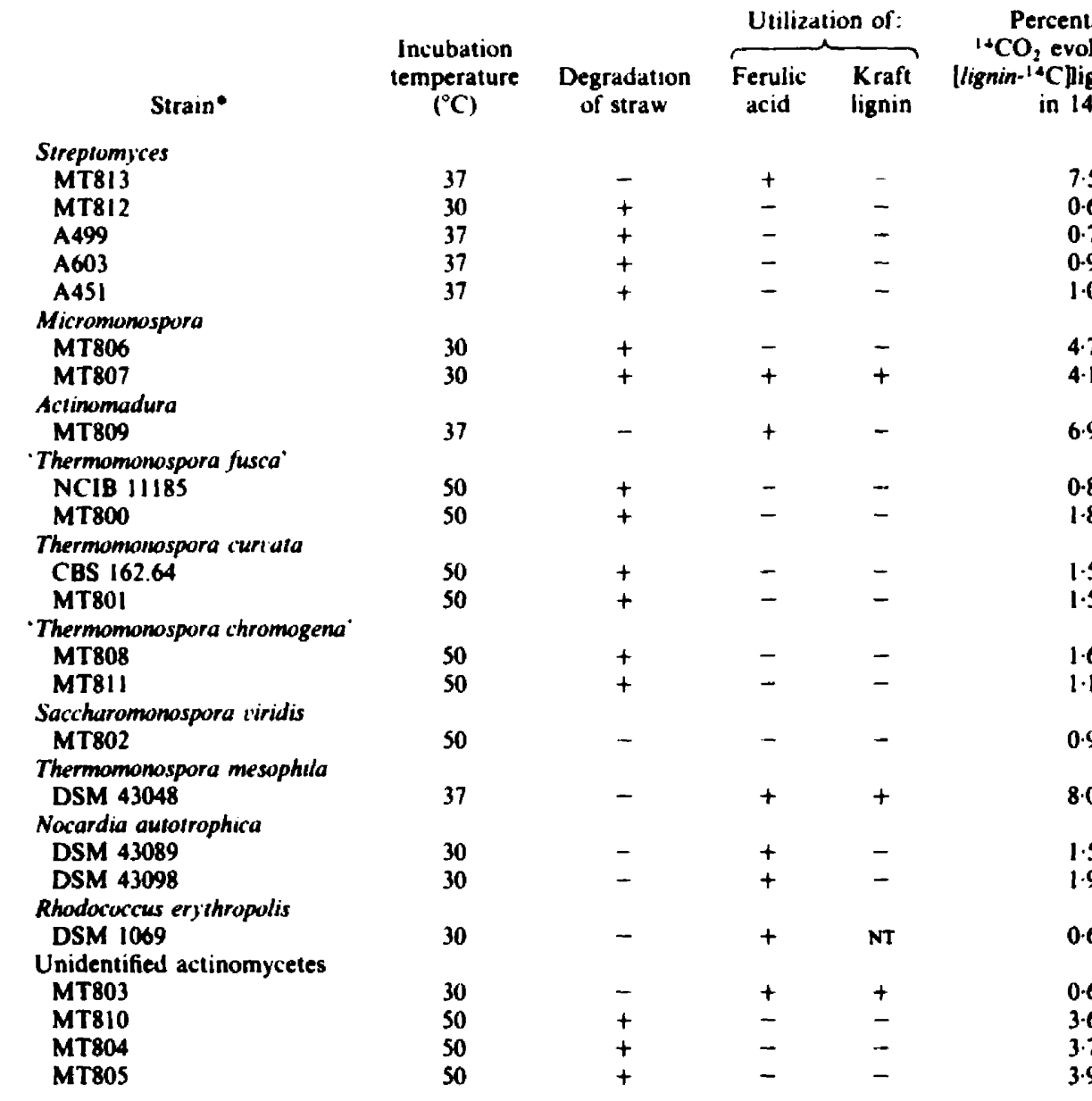

NT, Not tested.

- NCIB, National Collection of Industral Bacteria, Torry Research Station, Aberdeen, UK: CBS, Centraalbureau voor Schimmelcultures, Baarn, The Netherlands; prefix A. received from Dr J. Lacey, Rothamsted Experimental Station. Herts, UK: DSM, Deutsche Sammlung von Mikroorganismen, Grisebachstrasse 8, D-3400 Gottingen, FRG: MT, UMIST culture collection.

+ Uninoculated controls evolved approximately $0.6 \%{ }^{14} \mathrm{CO}_{2}\left(30^{\circ} \mathrm{C}\right.$ and $\left.37{ }^{\circ} \mathrm{C}\right)$ and $0.8 \%{ }^{14} \mathrm{CO}_{2}\left(50{ }^{\circ} \mathrm{C}\right)$ from [lognin-14 C) lignocellulose in $14 \mathrm{~d}$.

parameter in both Phanerochaete chrysosporium where $1 \mathrm{~g} \mathrm{I}^{-1}$ severely represses lignin degradation (Ander $e t$ al., 1983) and Stm. badius, where ligninolytic activity is optimal at $7 \mathrm{~g}$ yeast extract $1^{-1}$ (Barder \& Crawford, 1981); possible effects of yeast extract on growth were not taken into account. In cultures of Streptomyces sp. MT813, ${ }^{14} \mathrm{CO}_{2}$ evolution and visible growth were unaffected by yeast extract concentration, whereas in $\mathrm{Thm}$. mesophila, $8 \%{ }^{14} \mathrm{CO}_{2}$ was evolved in $14 \mathrm{~d}$ at $0.5-2.0 \mathrm{~g} \mathrm{I}^{-1}$ but only $5.2 \%{ }^{14} \mathrm{CO}_{2}$ in the absence of yeast extract, where visible growth was also reduced. Although growth was only estimated visually, it is suggested that the effect of yeast extract on ${ }^{14} \mathrm{CO}_{2}$ evolution by $\mathrm{Thm}$. mesophila is simply the result of an effect on growth.

Degradation of lignin to ${ }^{14} \mathrm{CO}_{2}$ by both strains was largely unaffected by cultural conditions. When cultures were grown in air rather than $100 \% \mathrm{O}_{2}$ or grown in shake flasks, there was no significant change in the extent of ${ }^{14} \mathrm{CO}_{2}$ evolution (Table 2). However, in both organisms, 
Table 2. Effect of cultural parameters on ${ }^{14} \mathrm{CO}_{2}$ evolution from [lignin- ${ }^{14} \mathrm{C}$ lignocellulose by actinomycetes

Growth conditions

Stationary in $100 \% \mathrm{O}_{2}$

Stationary in air

Shaking in $100 \% \mathrm{O}_{2}$

Dry-autoclaved lignocellulose* $\uparrow$

Cellulase-treated lignocellulose" $\downarrow$

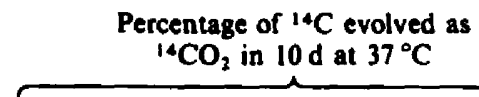

Streptomyces sp. MT813

Thm. mesophila

5.9

$6 \cdot 3$

$5 \cdot 5$

6.5

4.5
$7 \cdot 3$

7.1

$7 \cdot 0$

$7 \cdot 3$

6.5

- Cultures grown stationary in $100 \% \mathrm{O}_{2}$.

$+\left[\right.$ lignin ${ }^{-1} \mathrm{C}$ ) Lignocellulose autoclaved dry at $121^{\circ} \mathrm{C}$ for $3 \mathrm{~h}$.

$\$\left[\right.$ lignin-1 $\left.{ }^{4} \mathrm{C}\right] \mathrm{Lignocellulose}$ treated twice with Trichoderma cellulase to remove carbohydrate esters of phenolic acids.

shake-flask cultures initially exhibited a larger amount of visible growth. Consequently, after $41 \mathrm{~h}{ }^{14} \mathrm{CO}_{2}$ values were approximately twofold greater than in stationary cultures in which the rate of ${ }^{14} \mathrm{CO}_{2}$ evolution later increased so that equivalent amounts of ${ }^{14} \mathrm{CO}_{2}$ were detected after $88 \mathrm{~h}$, irrespective of culture conditions. Similarly, [/ignin-14 C]lignocellulose, autoclaved dry to minimize disruption of the native structure, was found to be equally susceptible to degradation by the actinomycetes. However, when ${ }^{14} \mathrm{C}$-labelled phenolic acids esterified to carbohydrate were removed by cellulase treatment, a decrease in ${ }^{14} \mathrm{CO}_{2}$ evolution from the radiolabelled substrate was observed (Table 2). The reproducibility of this effect was not determined but was more pronounced in the culture of Streptomyces sp. MT813 and may be related to the ability of this organism to utilize ferulic acid but not Kraft lignin.

The amount of ${ }^{14} \mathrm{C}$ solubilized in the culture medium during actinomycete attack on [lignin${ }^{14} \mathrm{C}$ llignocellulose was considerably greater than the amount of ${ }^{14} \mathrm{CO}_{2}$ evolved. In both strains, ${ }^{14} \mathrm{CO}_{2}$ was rapidly evolved during the first $72 \mathrm{~h}$ of growth, after which the rate of ${ }^{14} \mathrm{CO}_{2}$ production declined (Fig. 1). Soluble- ${ }^{14} \mathrm{C}$ levels also rose dramatically during the first $72 \mathrm{~h}$ to $30-40 \%$ of the total added as [lignin- ${ }^{14} \mathrm{C}$ ]lignocellulose, and although ${ }^{14} \mathrm{CO}_{2}$ continued to be produced after this time, no further solubilization occurred (Fig. 1). This soluble ${ }^{14} \mathrm{C}$-labelled material was found to be relatively resistant to actinomycete degradation to ${ }^{14} \mathrm{CO}_{2}$ since only $2 \cdot 0-2 \cdot 5 \%$ was converted to ${ }^{14} \mathrm{CO}_{2}$ when it was added to fresh cultures. In uninoculated controls, the soluble ${ }^{14} \mathrm{C}$ value of approximately $4 \%$ remained constant throughout the experiment. Thm. mesophila, which has a slower growth rate than the Streptomyces sp., showed a lag period of approximately $20 \mathrm{~h}$ before visible growth, ${ }^{14} \mathrm{CO}_{2}$ and solubilized ${ }^{14} \mathrm{C}$ were detected. A similar but much longer lag period (72 h approx.) was observed with other ligninolytic strains (MT806, MT807, MT809) but in all cases commencement of ${ }^{14} \mathrm{CO}_{2}$ evolution coincided with the appearance of visible growth.

\section{DISCUSSION}

A number of workers have suggested a correlation between the degradation of native lignin and other, less complex substrates, usually in an attempt to provide routinely applicable primary screening methods (Sundman \& Näse, 1971; Phelan et al., 1979; Deschamps et al., 1981). However, we found that ligninolytic activity could not be inferred from either the degradation of ballmilled straw, which is an indication of cellulolysis, or the utilization of lignin-related phenolic compounds. The thermophilic actinomycetes Thm. curvata and ' $T \mathrm{hm}$. fusca', isolated in large numbers from mushroom compost, and the most active straw-degrading actinomycetes studied here, were incapable of degrading [ ${ }^{14} \mathrm{C}$-labelled wheat lignin. In a similar experiment using [ ${ }^{14}$ C]lignin-labelled oak and maple lignocellulose, Crawford \& Crawford (1976) also found that 'Thm. fusca' did not degrade lignin. Cellulolytic activity has been described previously in the genus Micromonospora (Sandrak, 1977), the other major group of straw-degrading actinomycetes 


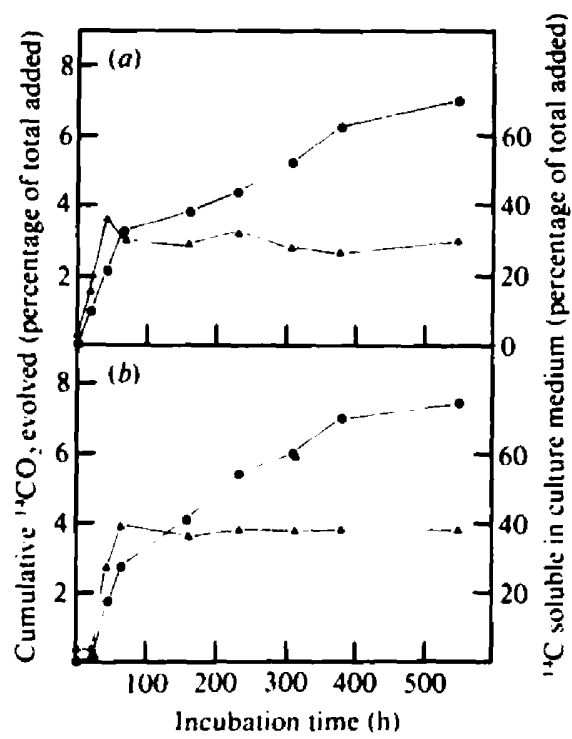

Fig. 1. [lignin-1 ${ }^{14} \mathrm{C}$ lLignocellulose solubilization and degradation to ${ }^{14} \mathrm{CO}_{2}$ by actinomycetes. (a) Streptomyces sp. MT 813, (b) Thm. mesophila DSM 43048. O, ${ }^{14} \mathrm{CO}_{2} ; \Delta$, soluble ${ }^{14} \mathrm{C}$.

isolated here, but this is the first indication that these slow-growing organisms can attack lignin. Micromonosporas form a significant component of the actinomycete population in natural substrates and can be efficiently isolated by incorporating novobiocin in the isolation medium, allowing direct observation of colonies surrounded by zones of straw degradation.

Generally higher levels of ligninolytic activity were observed in strains selected for their ability to grow on phenolic compounds, but again several ferulic-acid- and Kraft-lignin-degrading organisms showed little or no activity against radiolabelled wheat lignin. The latter included strains of Nocardia autotrophica and Rhodococcus erythropolis, which had previously been found to be ligninolytic when tested against corn stalk and synthetic lignins (DHP) specifically $\left[{ }^{14} \mathrm{C}\right]-$ labelled in the side chain, aromatic ring or methoxyl positions (Trojanowski et al., 1977; Haider et al., 1978). This may be partly due to the absence of ${ }^{14} \mathrm{C}$ in the methoxyl groups of the wheat lignin used in this study, but is more likely to be a reflection of variations in the degradability of different $\left[{ }^{14} \mathrm{C}\right.$ lignin preparations.

The physiology of lignin attack by white-rot fungi is well documented and it has been shown that the degradation of [ ${ }^{14} \mathrm{C}$ lignin-labelled wheat lignocellulose by these organisms proceeds in a similar manner to the degradation of wood and synthetic lignins (McCarthy et al., 1984). In this study, we have found that wheat-lignin degradation by two selected actinomycetes, $T \mathrm{hm}$. mesophila and a Streptomyces sp., does not exhibit the established characteristics of white-rot fungal attack on lignin. Lignin degradation by white-rot fungi is severely inhibited in shaking cultures or when stationary cultures are flushed with air rather than $40-100 \% \mathrm{O}_{2}$ (Kirk \& Fenn, 1982), but these parameters had no significant effect on the actinomycete cultures. The secondary metabolic nature of ligninolytic activity in white-rot fungi (Kirk \& Fenn, 1982) results in a delay in the onset of ${ }^{14} \mathrm{CO}_{2}$ evolution while primary growth is completed. In contrast, evolution of ${ }^{14} \mathrm{CO}_{2}$ by the actinomycetes always accompanied growth and was concentrated on the first $72 \mathrm{~h}$, suggesting that attack on lignin occurs during the primary growth phase in these organisms. Solubilization of ${ }^{14} \mathrm{C}$ also increased rapidly during this period and the figure of $30-40 \%$ soluble ${ }^{14} \mathrm{C}$ after $72 \mathrm{~h}$ is higher than observed previously for ligninolytic actinomycetes (Phelan et al, 1979) but comparable to Phanerochaete chrysosporium grown on radiolabelled aspen wood for $30 \mathrm{~d}$ (Reid et al., 1982).

However, in concluding that these actinomycetes are particularly efficient lignin degraders, the nature of both the lignin preparation used and the soluble products must be taken into ac- 
count. Grass lignins are characterized by the presence of esterified phenolic acids (Higuchi $\boldsymbol{e t}$ al., 1967) and are probably more susceptible to biological attack than those of woody plants (Crawford, 1981). Removal of phenolic acids linked to carbohydrate did not have a major effect on ${ }^{14} \mathrm{C}$ solubilization (data not shown) or ${ }^{14} \mathrm{CO}_{2}$ evolution, and the amount of ${ }^{14} \mathrm{C}$-labelled phenolic acids associated with the lignin component (McCarthy et al., 1984) could not account for the total ${ }^{14} \mathrm{CO}_{2}$ evolved. Furthermore, the suggestion that sterilization of lignocellulose in liquid medium could lead to considerable solubilization (Crawford, 1981), and presumably a more degradable substrate, was found not to apply to the degradation of ${ }^{14} \mathrm{C}$-labelled wheat lignin (see Table 2).

The water-soluble radiolabelled material cannot be totally equated with lignin breakdown products since it is possible that modifications introduced by the actinomycetes may have affected lignin solubility. This view is consistent with the detection of both low molecular weight aromatic compounds and a water-soluble lignin-derived polymer in culture supernatants of Stm. viridosporus grown on corn lignocellulose (Crawford, 1981 ; Crawford et al., 1983). In both Thm. mesophila and the Streptomyces sp., the level of water-soluble ${ }^{14} \mathrm{C}$ stabilized after $72 \mathrm{~h}$ and was not substantially degraded to ${ }^{1+} \mathrm{CO}_{2}$ in fresh cultures. This suggests the presence of a lignin-derived polymer resistant to further degradation and we have preliminary evidence that most of the ${ }^{14} \mathrm{C}$-labelled material has a molecular weight of approximately 10000 .

The number of actinomycetes implicated as having a role in the recycling of lignin in natural substrates can now be extended to include representatives of several distinct genera. While the values for ${ }^{+} \mathrm{CO}_{2}$ evolution from [ ${ }^{1+} \mathrm{C}$ ]lignin-labelled wheat lignocellulose reported here are much lower than those observed with white-rot fungi (McCarthy et al., 1984), they are nevertheless significant. Optimization of culture parameters could lead to improved ligninolytic activity but in natural substrates which contain a large and diverse actinomycete population it is likely that interactions between different species will result in a much more extensive degradation of lignocellulose. Pure cultures could nevertheless be genetically manipulated to alter the regulation of ligninolytic activity and achieve the levels of degradation and range of transformations found in natural environments.

This work was part of a programme supported jointly by British Petroleum's Venture Research Unit and the Agriculture and Food Research Council. We thank Edwin Peace for technical assistance with the radiometric assay.

\section{REFERENCES}

Ander, P., Ericsson, K.-E. \& YU, H.-S. (1983). Physiological requirements for degradation of lignin and lignin-related substances by Sporotrichum pulverulentum. European Journal of Applied Microbiology and Biorechnology 18, 374-380.

Antal, S. P. Crawpord, D. L. (1981). Degradation of softwood, hardwood and grass lignocelluloses by two Streptomyces strains. Applied and Environmental Microbiology 42, 378-380.

AtHalye, M., Goodfellow, M., Blakey, L. \& LACEY, J. (1980). Selective isolation of Actinomadura and related actinomycetes from soil. Journal of Applied Bacteriology 48, xv.

Barder, M. J. \& Crawford, D. L. (1981). Effects of carbon and nitrogen supplementation on lignin and cellulose decomposition by a Streptomyces. Canadian Journal of Microbiology 27, 859-863.

Crawpond, D. L. (1978). Lignocellulose decomposition by selected Streptomyces strains. Applied and Environmental Microbiology 35, 1041-1045.

Crawpord, D. L. (1981). Microbial conversions of lignin to useful chemicals using a lignin-degrading Streptomyces. Biotechnology and Bioengineering Symposinu 11, 275-291.
Crawford, D. L. \& Crawpord, R. L. (1976). Microbial degradation of lignocellulose: the lignin component. Applied and Environmental Microbiology 31, 714-717.

Crawpord, D. L., Pometto. A. L., III \& Crawford, R. L. (1983) Lignin degradation by Streptomyces viridosporus: isolation and characterisation of a new polymeric lignin degradation intermediate. Applied and Environmental Microbiology 45, 898 -904.

Cross, T. (1968). Thermophilic actinomycetes. Journal of Applied Bacteriology 31, 36-53.

Deschamps, A. M., Gillie, J. M. \& Lebeault, J. M. (1981). Direct delignification of untreated bark chips with mixed cultures of bacteria. European Journal of Applied Microbiology and Biotechnology 13, 222-225.

ForNeY, L. J., Reddy, C. A., Tien, M. \& Aust, S. D. (1982). The involvement of hydroxyl radical derived from hydrogen peroxide in lignin degradation by the white-rot fungus Phanerochaete chrysosporium. Journal of Biological Chemistry 257, 11455-11462.

Hajder, K., Troianowski, J. \& Sunduan, V. (1978). Screening for lignin degrading bacteria by means of 'CC-labelled lignins. Archives of Microbiology 119, 103-106. 
Higuchi, T., Ito, T., Shimada, M. \& Kawamura, I. (1967). Chemical properties of milled wood lignin of grasses. Phytochemistry 6, 1551-1556.

KIRK, T. K. \& FENN, P. (1982). Formation and action of the ligninolytic system in basidiomycetes. In Decomposer Basidiomycetes, pp. 69-90. Edited by J. C. Frankland, J. N. Hedger M. J. Swift. Cambridge: Cambridge University Press.

LACEY, J. (1973). Actinomycetes in soils. composts and fodders. In Actinomycetes: Characteristics and Practical Importance, pp. 231-251. Edited by G. Sykes \& F. A. Skinner. London: Academic Press.

MCCARthy, A. J. \& Cross. T. (1981). A note on a selective isolation medium for the thermophilic actinomycete Thermomonospora chromogena. Journal of Applied Bacteriology 51, 299-302.

MCCarthy, A. J. \& Cross, T. (1984). A taxonomic study of Thermomonospora and other monosporic actinomycetes. Journal of General Microbiology 130 , 5-25.

McCarthy, A. J., MacDonald, M.J., Paterson, A. \& BrodA, P. (1984). Degradation of [ ${ }^{4}$ Clligninlabelled wheat lignocellulose by white-rot fungi. Journal of General Microbiology 130, 1023-1030.

Orchard, V. A. (1980). Long term effect of sewage sludge additions on populations of Nocardia asteroides, Micromonospora and Thermoacinomyces in soil. Soil Biology and Biochemistry 12. 477-482.

Phelan, M. B., Crawford, D. L. \& Pometto, A. L., III. (1979). Isolation of lignocellulose-decomposing actinomycetes and degradation of specifically ${ }^{1+C} \mathrm{C}$. labelled lignocellulose by six selected Streptomyces strains. Canadian Journal of Microbiology 25, 1270 1276.

Reid. I. D., Abrams, G. D. \& Pepper, J. M. (1982). Water-soluble products from the degradation of aspen lignin by Phanerochaete chrysosporium. Canadian Journal of Botany 60, 23572364.

Rowbotham, T. J. \& Cross, T. (1977). Ecology of Rhodococcus coprophilus and associated actinomycetes in fresh water and agricultural habitats. Journal of General Microbiology 100, 231-240.

SANDRAK. N. A. (1977). Cellulose decomposition by Micromonosporas. (In Russian with English summary). Mikrobiologiya 46, 478-481.

Stutzenberger, F. J. (1972). Cellulolytic activity of Thermomonospora curvata: nutritional requirements for cellulase production. Applied Microbiology 24, 77-82.

SUNDMAN, V. \& Näse, L. (1971). A simple plate test for direct visualisation of biological lignin degradation. Papperi Ja Puu 2, 67-71.

TIEN. M. \& KIRK, T. K. (1983). Lignin degrading enzyme from the hymenomycete Phanerochaele chrysosporium Burds. Science 221, 661-663.

Trojanowski, J., Haider, K. \& SundMan, V. (1977). Decomposition of ${ }^{14} \mathrm{C}$-labelled lignin and phenols by a Nocardia sp. Archives of Microbiology 114, 149-153.

Waksman, S. A. CORDON, T. C. (1939). Thermophilic decomposition of plant residues in composts by pure and mixed cultures of microorganisms. Soil Science 47, 217-224. 